\title{
TRANSFORMATIVE LEADERSHIP EDUCATION USING ARTS-BASED STORYTELLING
}

\section{Abstract}

Arts-based learning is a powerful approach that leadership educators should consider to enrich student learning. By employing an arts-based storytelling pedagogy, leadership educators can engage learners in the power of their lived experiences (Sutherland \& Jelinek, 2015). At a large Midwestern research university, leadership educators have utilized an illustrative activity called the Little Buddy as a central pedagogical element to enhance student learning in regards to their cultural identity development and how this emerges in their understanding and practice of leadership. The Little Buddy activity is shaped and supported by literature in intercultural leadership, culturally relevant leadership learning, critical reflexivity, and arts-based narrative; and draws upon the power of storytelling as a pedagogy. Practitioner reflections and recommendations for practice will also be discussed.

\section{Introduction}

Arts-based learning is a powerful approach that leadership educators should consider to enrich student learning. As a type of experiential learning, arts-based learning occurs through deep reflection of lived experiences rather than focusing on objective analysis of data and articles (Estrella \& Forinash, 2007). This approach is enhanced when connected to the pedagogy of critically reflexive storytelling. Critical reflexivity asks participants to contextualize their experiences socially, culturally, and structurally, in order to better understand their connection to our social world (Fook \& Askeland, 2007). This means that leadership learners must consider how they engage in the practice of leadership and how leadership perpetuates or addresses asymmetrical power dynamics in oppressive systems. We posit that art provides an excellent opportunity for leadership education to explore, expose, and unpack lived experiences as a means of enhancing our understanding and practice of leadership.

By employing an arts-based storytelling pedagogy, leadership educators can engage learners in the power of their lived experiences (Sutherland \& Jelinek, 2015), and situate learners' experiences in the context of their social location (Ospina, 2019). This approach is transformative, especially in classrooms that employ a culturally relevant leadership learning framework or engage in the development of intercultural leadership. While these two approaches to leadership learning are particularly well-positioned to embrace an artsbased storytelling pedagogy, we argue that leadership educators grounded in any corner of the vast library of leadership theory can and should consider how this pedagogy can complement their teaching.

This paper will address how leadership educators at 
a large research university in the Midwestern region of the United States use arts-based storytelling as a leadership development tool. We teach an undergraduate-level course that explores how culture and social context impact the practice of leadership with special attention to systems of power and privilege. In our curriculum, we utilize an illustrative activity called the Little Buddy (see Figures 1 and 2) as a central element to engage learners in reflection about their cultural identity and experiences and how this shows up in their understanding and practice of leadership. In this paper, we will discuss the implementation of a semester-long artistic critical reflexivity activity as a tool for students to unpack their cultural and leadership identity. We will discuss how an arts-based curriculum fits within the theoretical and conceptual foundations of our classroom, share reflections on student learning connected to arts-based leadership learning, and explore recommendations for practice.

\section{Theoretical and Pedagogical \\ Framework}

The Little Buddy activity is shaped and supported by literature in intercultural leadership, culturally relevant leadership learning (CRLL), critical reflexivity, and arts-based narrative; and draws upon the power of storytelling as a pedagogy. Not only are learners afforded the opportunity to think about their own intercultural leadership identity, but doing so through an arts-based approach requires them to engage with their intercultural leadership identity development in a deep and critical way. Using a storytelling pedagogy to guide our work, learners then take their exploration a step further through sharing the story of their Little Buddy, and in essence their intercultural leadership identity development, with their classmates.

Intercultural Leadership Learning

Our conceptualization of intercultural leadership draws from literature on critical leadership studies, sociomateriality, adaptive leadership, leadership for social change, leadership identity development, intercultural learning, and culturally relevant leadership learning (CRLL). Through the integration of these theories, we believe that intercultural leadership offers an opportunity for leadership educators, learners, and practitioners to actively engage in building a more inclusive and socially just society.

Similar to CRLL's perspective that leadership education "seeks to transgress traditional boundaries of education and reframe leadership learning as a practice of freedom" (Osteen, Guthrie, \& Jones, 2016, p. 95), intercultural leadership situates the learning process of students squarely within their historical, structural, and organizational contexts. By employing this critical lens, leadership learning becomes a transformative pedagogy, which Mezirow (1997) defines as "the process of effecting change in a frame of reference" (p. 5). To this end, transformative learning challenges and transforms the identities of learners and promotes "personal development, deeper understanding, and increased [acceptance] and flexibility" (Illeris, 2015, p. 50). CRLL's approach is grounded in Day and Harrison's (2007) model of leader identity, which focuses on individual capacity and efficacy as a leader. It is important to note that while we see value in this conceptualization, intercultural leadership reflects a more collective perspective on leadership identity such as that reflected in Komives et al. (2005). Thus, while CRLL supports and frames The Little Buddy activity we employ, it is through a lens of collective, intercultural leadership that we seek to shape intercultural leadership learning activities.

A critical component of this collective lens is perspective-taking, which Deardorff (2011) describes as a common tenet of literature on intercultural development. Perspective-taking fits well with how we have conceptualized intercultural leadership, and is operationalized through the application of Hammer's 
(2012) intercultural development continuum (IDC). The developmental nature of intercultural learning lends itself to the concept that increased complexity in one's understanding of cultural commonalities and differences, through constant and intentional effort, leads to an increase in one's (a) ability to navigate interculturally and (b) self-efficacy related to this ability. A significant step in this developmental process is building cultural self-awareness, which we argue includes a critical understanding of how we objectively and subjectively experience the world. It is difficult to identify, understand, and appreciate cultural differences if we lack cultural self-awareness. The Little Buddy activity helps students develop intercultural leadership and humility through building this cultural self-awareness.

Arts-Based Leadership Development and Storytelling

Arts-based leadership development belongs to the family of experiential learning, learning that occurs through deep reflection of lived experience rather than logical learning that typically occurs from analyzing data and articles (Sutherland \& Jelinek, 2015). In artsbased learning, an aesthetic way of knowing is sought (Sutherland \& Jelinek, 2015). Arts-based learning is powerful due to its tendency to engage learners in what makes them human - emotions, feelings, and senses. As stated by Sutherland and Jelinek (2015), "The work around arts-based pedagogies strongly suggests this is fertile ground to throw off the cold, instrumental, hyper-rational shackles of traditional development approaches and to engage at a more fundamentally human level" (p. 14). Engaging in intercultural leadership identity development and cultural self-awareness is far from an instrumental, logical, or rational process. Rather, it involves engaging in deep and abstract reflection about cultural differences and commonalities that make up the experience of being human, a process that is supported by learning through the arts.

Taking an arts-based approach to leadership a step further, we also lean on the power of storytelling as a pedagogy. As a universal experience shared by all social groups, storytelling provides a common ground from which to build new knowledge (CarterBlack, 2007). Perhaps most importantly, storytelling provides a pedagogical framework out of which to fight oppression. As the system of oppression operates to disconnect and disassociate us, both the oppressed and the oppressors, from our personal and social histories, or our stories, sharing experiences of our personal and social histories through story reconnects us to them, and simultaneously raises our consciousness of social injustices (Senehi et al., 2009). Arts-based storytelling allows the opportunity for students to share stories about their cultural selves and their intercultural leadership identity expressed through art. These stories serve as a tool to raise the consciousness about our social world of both the storyteller and co-learners.

Critical Reflexivity

Reflexivity is a vital component of arts-based leadership development. In fact, Sutherland and Jelinek (2015) contend that arts-based activities alone are not enough for leadership development to occur. Engaged and intentional reflection about the experience is needed for sensemaking to follow. This is where true learning and growth happens. As expressed by Sutherland and Jelinek (2015), "To make the most of the learning opportunities happening, participants need space, time, and processes for reflexive work during and after learning interventions" (p. 14). Expressing one's intercultural leadership identity through art is itself a reflexive task, but continuing to reflect through the process of storytelling allows for even deeper learning and growth to take place. Critical reflexivity involves reflection of deep-seated assumptions about the social world with a focus on power dynamics (Fook \& Askeland, 2007). It asks participants to contextualize their experiences socially, politically, culturally, and structurally, in order to better understand their connection to our social world (Fook \& Askeland, 2007). 


\section{Description of Practice}

The Little Buddy (see Figures 1 and 2) is an illustrative storytelling activity that invites learners to get in touch with their inner child as a means to freely explore their intercultural leadership identity, hence the name, "Little Buddy." Drawing upon transactional analysis, which postulates that we all have an inner psyche comprised of the child, the adult, and the parent, the activity encourages learners to tap into the inner child as they consider their intercultural leadership identity from a place of curiosity, playful creativity, and openness (Berne, 1996). The Little Buddy activity holds a developmental focus that allows the learner to fully explore and unpack their own cultural identity development with unconditional positive regard (Rogers, 1957). The Little Buddy has been implemented in a semester-long, undergraduate-level leadership course that explores how culture and social context impact the practice of leadership with special attention to systems of power and privilege. It is an opportunity for learners to engage in critical reflexivity to consider how their lived experiences and social identities inform the way in which they practice leadership. Learners do not merely write down sentences describing their identities and experiences, they contemplate how to creatively represent these through illustrations or short phrases. The Little Buddy is an ongoing assignment of continuous refection. We reserve ten minutes at the end of each class session for learners to build on their understanding of their own story and reflect critically on their role in creating a more socially just, inclusive world.

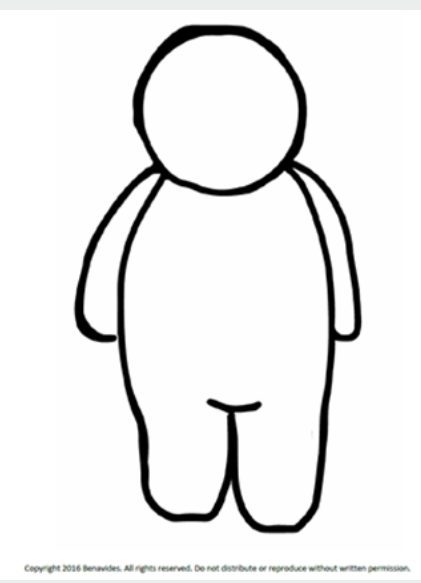

Figure 1. Blank Little Buddy

Note. This is the Little Buddy outline every student receives in the first class session.

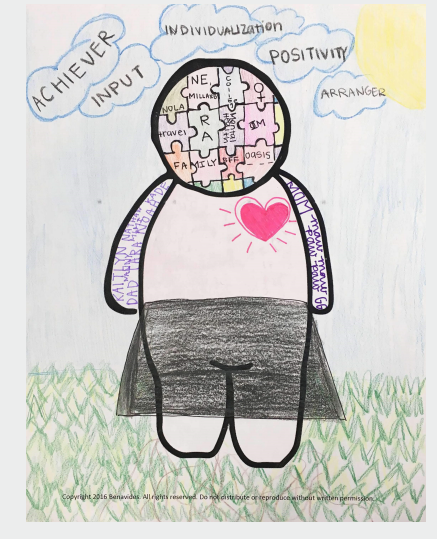

Figure 2. Completed Little Buddy

Note. This is an example of a completed Little Buddy at the end of the class.
The Little Buddy activity serves as the focal point of the final project, which is the creation of an intercultural leadership poster. The poster requires learners to host roundtable discussions with their peers in the style of a world café. Learners engage in storytelling about how they have come to understand their story, the practice of intercultural leadership, and how they can practice leadership to create and sustain inclusive spaces, and build bridges across cultures, in the future. 


\section{Outcomes and Results}

As leadership educators, we saw significant growth in learners who engaged in the Little Buddy activity. Although this growth looked different for different learners, in general there seemed to be a shift in learners' ability to articulate and visually represent the most salient aspects of their cultural and leadership identity. For example, one student said the following, "Upon entering the semester, you wanted us to write things or draw things that represent, like, who we are, as a person, as an intercultural leader. And so, the first week, I was like, 'Oh, no!' Because a lot of my life, I've been told, 'you don't really have culture.' And I was like, 'okay, I can see that.' But then, over the course of the semester, I learned that nobody's culture is exactly the same as everybody else's. And nobody can really tell you that you don't have a culture because your culture is just the traditions and the values and the things that make up who you are."

Additionally, after engaging in the Little Buddy activity, learners were more equipped to define their own cultural and leadership identity rather than allowing others to define it for them. One student remarked, "When I first came into the class, I [defined my culture around] what people told me about myself. That's what I put onto my first Little Buddy. But then, as the semester progressed and I progressed as a person through the skills we were learning, I realized that I'm more than just what people were telling me or what I grew up thinking that I was."

For others, the Little Buddy created space for intentional reflection about the concepts learned in class and how they could apply them in their own development and experiences. One learner said, "The Little Buddy Project contributed to my learning on many different levels. The concepts in class helped me understand my personal values and beliefs and how to grow into new ones within my Little Buddy. Without The Little Buddy Project I wouldn't have been able to reflect on these concepts and how I was starting to change progressively within the class."

\section{Practitioner Reflections}

The Little Buddy activity engages learners in a creative process of reflection as they consider who they are, how their social identities influence their role in practicing intercultural leadership, and how to represent themselves symbolically. Balancing challenge and support is one of the ways we stay attuned to the developmental needs of the learners in the classroom. In order for students to begin to evaluate and deconstruct systems of oppression, they first have to learn how to tell their own story. This self-awareness creates a foundation for them to then actively and authentically listen to the stories of culturally different others. Telling one's story and seeing oneself as a cultural being can be very challenging for students who may have limited experience going through the process of critical self-reflection regarding their own cultural identity and how this interacts with systems of oppression. Providing daily class time to work on the Little Buddy activity throughout the semester allows learners to consistently come into contact with their cultural story. While exploring their understanding of how culture has shaped their behaviors and beliefs, learners also engage in the process of unpacking their own power and privilege.

Through this process we realized the importance of building a classroom community that was conducive, and safe, for arts-based leadership development. Creating a transformative group dynamic emphasizing both small and large group cohesion was an important part of the delicate balance between challenge and support that allowed for the deepening and sharing of students' cultural identity stories to take place. In order to create this community, we learned the necessity of providing access to class readings, guest speakers, and other experiential educational opportunities for learners to experience the stories of historically underrepresented and underserved individuals without tokenization or misrepresentation. Perhaps even more important, we have reflected on our role as facilitators in such a community. We increasingly recognize the urgency for leadership educators to be committed 
to their own critical self-reflection and modeling this authentically in the classroom and in their daily lives. Doing so creates a learning experience where all classroom participants (both the teachers and the learners) engage in leadership development in a reciprocal and co-constructed process of collective storytelling that results in intercultural exploration, discovery, and transformation.

\section{Recommendations for Practice}

Incorporating the Little Buddy activity into a course focused on developing learners' intercultural leadership has proven quite valuable. Learners do not always initially understand the transformative impact of the Little Buddy and may not take it seriously. As a result, leadership educators should model the importance of arts-based introspection by providing space and time for deep reflection and expression through art. While the Little Buddy activity uses words, pictures, and other symbolic representations to illustrate participants' intercultural leadership identity, other forms of art such as creative writing, video blogs, music, dance, poetry, and painting could also be incorporated into arts-based leadership development approaches (Sutherland \& Jelinek, 2015). As a way of knowing that is rooted in marginalized communities, arts-based leadership development and storytelling are supported by CRLL (Jones et al., 2016) and should be further explored as approaches to leadership development that promote inclusivity in the learning community. Future research on artsbased leadership development should focus on understanding the process of creating communities in which participants are able to fully engage in artsbased activities that require them to try something new, be open to failure, trust themselves and others, and be vulnerable (Sutherland \& Janlinek, 2005).

\section{Conclusion}

The combined power of the arts and storytelling has been an incredible pedagogy in teaching leadership, especially leadership focused on social change and equity. We have found that tying this pedagogy to culture and critical thinking has had significant impact on learners' integration of leadership into their sense of self. In order for students to begin to evaluate and deconstruct systems of oppression, they first have to learn how to tell their own story. Using this approach in a thoughtful and intentional manner, leadership educators can deepen learners' understanding and practice of leadership by making meaningful connections to lived experiences. 


\section{References}

Berne, E. (1996). Principles of transactional analysis. Indian Journal of Psychiatry, 38(3), 154-159.

Carter-Black, J. (2007). Teaching cultural competence: An innovative strategy grounded in the universality of storytelling as depicted in African and African American storytelling traditions. Journal of Social Work Education, 43(1), 31-50. https://doi.org/10.5175/JSWE.2007.200400471

Day, D. V. \& Harrison, M. M. (2007). A multilevel, identity-based approach to leadership development. Human Resource Management Review, 17(4), 360-373. https://doi.org/10.1016/j.hrmr.2007.08.007

Deardorff, D. K. (2011). Assessing intercultural competence. New Directions for Institutional Research, 2011(149), 65-79. https://doi.org/10.1002/ir.381

Estrella, K., \& Forinash, M. (2007). Narrative inquiry and arts-based inquiry: Multinarrative perspectives. Journal of Humanistic Psychology, 47(3), 376-383. doi: 10.1177/0022167807301898

Fook, J. \& Askeland, G. A. (2007). Challenge of critical reflection: 'Nothing ventured, nothing gained.' Social Work Education, 26(5), 520-533. https://doi.org/10.1080/02615470601118662

Hammer, M. R. (2012). The intercultural development inventory: A new frontier in assessment and development of intercultural competence. In M. Vande Berg, R.M. Paige, \& K.H. Lou (Eds.), Student learning abroad (pp. 115-136). Stylus Publishing.

Illeris, K. (2015). Transformative learning in higher education. Journal of Transformative Learning, 3(1), 46-51. Retrieved from https://jotl.uco.edu/

Jones, B. J., Guthrie, K. L, \& Osteen, L. (2016). Critical domains of culturally relevant leadership learning: A call to transform leadership programs. New Directions for Student Leadership, 2016(152), 9-21. https://doi. org/10.1002/yd.20205

Komives, S. R., Owen, J. E., Longerbeam, S. D., Mainella, F. C., Osteen, L. (2005). Developing a leadership identity: A grounded theory. Journal of College Student Development, 46(6), 593-611. https://doi. org/10.1353/csd.2005.0061

Mezirow, J. (1997). Transformative learning: Theory to practice. New Directions for Adult and Continuing Education, 74, 5-12. https://doi.org/10.1002/ace.7401

Osteen, L., Guthrie, K. L, \& Jones, B. J. (2016). Leading to transgress: Critical considerations for transforming leadership learning. New Directions for Student Leadership, 2016(152), 95-106. https://doi.org/10.1002/ yd. 20212

Rogers, C. R. (1957). The necessary and sufficient conditions of therapeutic personality change. Journal of Consulting Psychology, 21(2), 95-103. https://doi.org/10.1037/h0045357

Senehi, J., Flaherty, M., Sanjana Kirupakaran, C., Kornelsen, L., Matenge, M., \& Skarlato, O. (2009). Dreams of our grandmothers: Discovering the call for social justice through storytelling. Storytelling, Self, Society, 5(2), 90-106. Retrieved from http://www.jstor.org/stable/41949022

Sutherland, I., \& Jelinek, J. (2015). From experiential learning to aesthetic knowing. Advances in Developing Human Resources, 17(3), 289-306. https://doi.org/10.1177/1523422315587894 